\title{
DOES DIET START TOMORROW? A DISCOURSE ANALYSIS OF SELF-DEPRECATING HUMOR AGAINST DIET CULTURE IN DIET STARTS TOMORROW
}

Astrid Restu Chaerani, *Junaidi

*Corresponding Author

English Studies Program, Universitas Indonesia

junaidi@ui.ac.id

\begin{abstract}
The hegemonic diet culture has recently become ruled out due to its painful methods of losing weight and its bad side effect for health. However, it is hardly denied that many women still put their body weight as a big matter due to the perpetuated portrayal of slim female figures throughout visual media. This article contains a discourse analysis of the Instagram page Diet Starts Tomorrow (@ dietstartstomorrow), a humor-branded page reflecting upon female's daily life that tends to involve diet culture in it throughout textual jokes. Data obtained from numbers of humorous text contain self-criticism, rejection, and circumvention of so-called healthy lifestyle written and posted by mostly female speakers. Through Gramscian lens, it is explored that self-deprecating humor articulates young women's resistance towards the diet culture. Selfdeprecation primarily serves as a comfort space for young women, boosts self-confidence, and creates mutual understanding between audiences through unveiling their emotional vulnerability. The results of the study refer to the humorous self-deprecatory text as a critique towards strict diet methods and beauty standards, for example by not judging female who keep consuming junk food or large portions of food. The research suggests further examination on how language is utilized to empower fat movement within the society of both gender.
\end{abstract}

Keywords: diet program, fat movement, self-deprecation, social media, textual joke

\section{INTRODUCTION}

To dig in and understand how a certain social practice occurs, language is the first thing to observe. Language becomes a source as well as a tool that could support researchers' observation. In order to do that, they utilize an approach to their analysis, which is discourse analysis. According to Paltridge (2006), discourse analysis aims to seek for knowledge about language beyond the word, clause, phrase, and sentence that is essential to achieve successful communication. Discourse analysis has apparently been utilized as an approach to many social practice, including advertisement, movies, humor, magazines, gender issues, even racism. This certainly opens up a greater opportunity for other, more complex social practices to be observed and understood.

Diet culture has long been a part of our lifestyle which recently became the paradigm fought by health experts regarding the methods of its application that burden the individual. According to Harrison (2018), diet culture is "a system of beliefs that worships thinness" that it "equates to health and moral virtue". It also "promotes weight-loss as a means of attaining higher status". Meanwhile, Bell (2018) claimed that "diet culture also contributes to a state of mind that can lead to problematic emotional eating, binge cycling, and many more". Moreover, Clodfelter-Mason (2019) argued that "among many things, diet culture's influence can lead to developing weight bias which is having unfavorable thoughts about people due to their body size or weight". It is also unfortunate knowing that to fight against diet culture is a hard thing to do, since 
people can find it everywhere near them: from the amount of calories written on a menu, to diet talk during lunch, or even topics regarding clean-eating (Bell, 2018). These diet culture outcomes obviously encourage their participants to focus more on their body mass and set aside the other matters including physical as well as mental health. Apparently, the irony lies on the reality that often, this diet notion is associated with healthy behaviors, which makes it difficult for people to distinguish which strategy should better be chosen since they already perceive that it requires a thin body to be healthy.

Consequently, this paradigm has created a misperception, especially among women who are struggling to seek for either the physical wellness or confidence within their shape and body image, leading them to eventually decide to stick with diet culture. Recent studies have explored the motives behind the perpetuation of the paradigm, and social media has apparently become one that plays a big role. An online experiment was conducted by Levallen and Behm-Morawitz (2016), involving 118 US-based women to an exposure of fitness images posted on Pinterest, a social networking website. The results revealed that participants tracking more fitness panels on the website are more expected to proclaim the plan in participating extreme weight-loss activities. The use of social media, particularly Facebook, is related to concerns among young women regarding body image as well (Fardouly \& Vartanian, 2016; Eckler, Kalyango, \& Paasch, 2017). Similarly, acquaintance with celebrity and peer images on Instagram "increased negative mood and body dissatisfaction" (Brown \& Tiggermann, 2016). Larger consumption of Instagram fitness feeds was also linked to "greater selfobjectification" interceded through internalization as well as "appearance comparisons" toward either public figures or female model in fitspiration pictures (Fardouly, Willburger, \& Vartanian, 2017). These facts clearly show that the ideal depiction of female body posted on social media has become a powerful instrument in shaping women's negative perception towards their own body image.

Knowing that the widespread depiction of the ideal body shape of women through images and weight-loss hacks on social media has brought negative impact to both physical and psychological condition of particularly the female audience, several self-love movements were made. According to Cohen et al. (2019), subject regarding body-positive, particularly on social media, strives for confronting typical beauty standards as well as nurturing females to accept and feel pleased about their unique type of bodies. For instance, Webb et al. (2017) conducted a research about fat-accepting lifestyle and managed to analyze numbers of fatspiration feeds on Instagram which varied in terms of the strategies in portraying fat females, and discovered that it was one constructive way to promote body acceptance. Similarly, Cohen et al. (2019) conducted a content analysis on 640 Instagram posts from famous self-love pages that were associated with body positivity and explored that "body positive imagery typically depicted a broad range of body sizes and appearances". A short acquaintance to body positive-related posts was also supplementary towards enhancements in young women's positive vibes, satisfaction as well as appreciation towards their body, qualified with "thin-ideal" and "appearance-neutral" posts (Cohen et al., 2019). Meanwhile, a comparative content research on fat body representations through hashtags also explored that the use of \#curvyfit and \#curvyyoga indicated a positive improvement in 
how every type of body shape is represented in social media, particularly Instagram (Webb et al., 2019). This leads to a conclusion that the propagation of body positivity movements are done mostly throughout appearance-based contents.

While a number of previous studies offering analysis of how pictures of body with various shapes and sizes and other visual works uploaded on social media have helped promote body-positive and self-acceptance movement, little discussion has been done regarding humor as one element in fighting social construct. In addition, research on predominantly self-deprecatory text as a tool for expressing love for oneself as well as criticism towards diet culture still needs to be done. Considering that a new consciousness is needed in order to construct and preserve a new society (Gramsci, 1971), body positivity and fat movement are two minor ideology that have been struggling to survive while dominated by the massive paradigm of diet culture. This article will examine a series of humorous self-deprecatory text that are documented in a humor-branded Instagram account Diet Starts Tomorrow (@dietstartstomorrow), and how it functions as a device to articulate young women's resistance towards thin-ideal paradigms that have long been rooted within the society. This article will also offer a discussion about how humorous self-deprecatory text serves as an attitude as well as perception of particularly young women towards diet culture and beauty standards.

In everyday social interactions, humor becomes one of the important aspects related to the social competition and a tool to prove identity and character, especially among women. Although there has been little expansion in the sociolinguistics studies on humor within the domain of gender studies (Holmes \& Schnurr, 2006; Corts-Conde $\&$ Boxer, 2010) which in a way revealed the bitter fact that women still have to put extra effort in facing the "socially imposed gender roles" (Matwick \& Matwick, 2017), the exceptional nature of humor has been recognized to build a constructive instrument to reinforce gender deconstruction (Crawford, 2003). In an experimental study conducted by Tosun, Faghihi, and Vaid (2018), it is observed that women have apparently become more able to be seen in a quantity of public life domains, involving "the realm of comedy". It is also suggested that, according to Crawford (2003), resistance to overbearing gender's social construction can be articulated within the dogmatic humor of the women's movement and in the colloquial humor of women acquaintances. Green (1998) stated that "shared humor between women in leisure contexts can be a source of empowerment and resistance to gender stereotypes, the study of which, assists in illuminating the process of gender identity construction" ( $p$. 171). Green added that, in certain situations, women benefit from humor in support of sexist imagery subversion (Green, 1998).

According to Apte (1985) and Greengross and Miller (2008), self-deprecating humor has become one of the most widespread forms of humor among the other varieties of it. Matwick and Matwick (2017) in their research about self-deprecatory humor on TV cooking shows claimed that self-deprecating humor is "a form of selfdisclosure" (p. 33), emphasizing that "humorous self-deprecation is self-directed critique done in a humorous way to minimize possible value judgment that the selfrevealing information might provoke" (p. 33). It is also explored that to laugh at oneself is a helpful way to become persistent while facing a work task (Cheng \& Wang, 2016). Furthermore, realizing that other-deprecating humor might not be a friendly type of 
humor to perform since it is established by insulting other people (Greengross \& Miller, 2008), self-deprecating humor is assumed to be the less aggravating and more helpful approach to predispose behavioral intention (Lee, Slater, \& Tchernev, 2015). Matwick and Matwick (2017) in their study reinforced that humor containing self-deprecation serves as "an interpersonal linguistics resources" (p. 37) used by celebrities in order to connect with their audience. Also, celebrities make use of self-deprecating humor to draw attention to "stereotypical gender behavior" (Matwick \& Matwick, 2017, p. 33).

\section{METHOD}

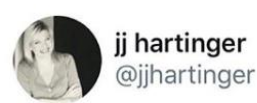

I'm currently helping my husband look for his chocolates that I ate last Friday.

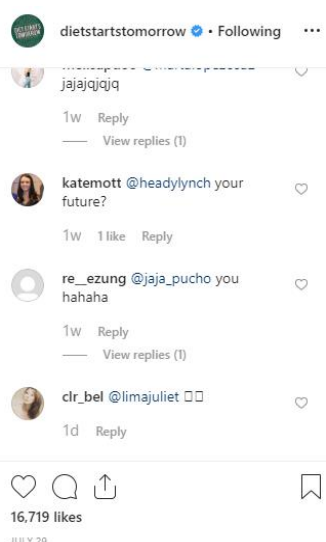

Figure 1. Instagram 07/29/2019

In compiling this research, data acquisition was carried out qualitatively by relying on the content uploaded by a verified Instagram page Diet Starts Tomorrow (@ dietstartstomorrow), which are mostly in the form of text. The account is powered by Betches, a digital media company whose brand is established into a large humor category reflecting upon themes such as public figures, health and wellness, legislations, and movie reviews. Diet Starts Tomorrow serves as a platform that archives humorous text related to diet culture written by random social media users, especially Twitter users (see Figure 1). Most of the humorous text uploaded include viral diet quotes as well as quotes written by public figures. This study managed to collect the samples which are uploaded between January and July 2019. At the time of this writing, the account has uploaded 773 screenshots of mostly textual jokes and has gained 179,000 followers who are mostly female adolescents that would either give "like" to the posts or tag their friend's account at the comment section to show how relatable it is for them. Considering the research limitation, examining either the posts one by one or the interaction occurring between the users in the comment section wouldn't help point out the whole purpose of the study. Therefore, the author decided to feature only a number of posts that are felt to represent expressions about rejection towards the diet culture itself in order to understand the overall rhetorical purpose of this page. First, the author examined the diction and the rhetoric used in the text. After that, the author put the examination into explanation, referring each discourse to ones from daily life. Taking Figure 1 as a sample, the text uses a rhetoric in order for the audience to get another impression towards the speaker. There, the speaker says "I'm currently helping my husband look for his chocolates", informing that she is trying to be 
helpful even though she admits the fact that she created the problem. This act of deprecating oneself brings a new perspective for those who are trying to find an affirmation within themselves.

\section{FINDING(S) AND DISCUSSION}

Social media has been observed to be one of several life matters that causes women to change their perspective towards their own body image. Discovering that the excessive portrayals of particularly perfect body image has brought negative impact towards both physical and psychological condition of women, a number of self-love movements were made, including ones created through social media platforms. Some create visual media such as paintings and comics, others share quotes related to selfacceptance. Based on the observation, Diet Starts Tomorrow is seemingly making a unique attempt on providing a comfortable space for its particular female audience who are struggling to find acceptance within themselves through humor sharing. The analysis discovered how self-deprecation is utilized as a tool to speak up what becomes somebody's physical imperfection that needs to be accepted. Throughout the discourse analysis, the author explored that self-deprecation is divided into two sections based on its function: self-deprecation as a comfort space for women, and self-deprecation as a form of refusal towards painful exercise and companionship. The analysis will elaborate how self-deprecation provides a room for women to express their true self in order to feel better about who they are, specifically when they are able to make decisions on what to consume and when they attempt to dodge several problems and arguments regarding diet in order to boost their self-confidence. The analysis will also explain how self-deprecation serves as a substitute for their voices that refuse to deal with painful exercise and social construct.

\section{Self-deprecation as a comfort space for women}

Overeating attitude: women's freedom in terms of consumption. Examining the page Diet Starts Tomorrow, it is found that overeating attitude becomes the most salient theme of the humor documented in the page. In this part of analysis, several lines from the list of posts were quoted, which are:

I. "According to this Mac and cheese box i'm a family of 4" (12/05/2019)

II. "Which girl in the office are you? I'm the one that asks everyone where they're going for lunch every half hour beginning from $10.30 \mathrm{am}$ " (29/03/2019)

III. "Why can't bags of chips make less noise? I don't need everyone to know what I'm doing at all times" (23/03/2019)

IV. "I just read a stat that the average person eats 46 slices pizza a year? This is the first time I've been above average at anything" (29/03/2019)

The act of deprecating oneself like text (I) brings up the notion that the speaker is capable of eating that much of mac and cheese, which is resulted from the pressure that society has given by assuming that it isn't proper for females to overeat. However, the statement sounds like the speaker doesn't have a problem with that, emphasizing that she deserves a freedom to admit how much she can eat by mentioning the exact portion of her food. Another lines of confession like text (II) and text (III) suggest a 
kind of deprecating oneself in a more affirmative way, where both speakers are somewhat pointing at themselves without sounding ashamed of the reality about them which they just stated. In text (II), the speaker tries to bring up her daily activity at the office, admitting that she is always in the urge of eating. Meanwhile, the speaker in text (III) uses a rhetoric in order to state that she can't stop snacking. Other statement of validation like text (IV) sounds like the speaker is trying to measure up a certain lifestyle fact with her personal reality as if both occurrences are comparable, indirectly confessing that she could eat more pizza than ever. What makes this line give different impression is with the rhetoric that the speaker is proud of what she does. These four humorous statements indicate that women can just decide their own ground rules in terms of food consumption. Here, particularly kinds of junk food are also mentioned in the lines, such as mac and cheese, chips, and pizza. This clearly denotes woman's cravings, which is often believed as unhealthy consumption that gives pleasure, increased body weight, and remorse, not long after the individual reaches their selfawareness. Meanwhile, expressing those overeating attitudes apparently helps woman audience in discharging their guilt tension of eating too much. To sum up, speaking up about overeating habit brings them a certain comfort for their minds.

Dodging statements: reflection of confidence. The next theme of humor that is explored in the page is the dodging or evasive statements regarding women's thoughts about themselves and the act of dieting. In order to avoid the reality that diet culture could be one decision for them to choose, speaking about what they are currently bearing including the fat they have on their body helps make them feel good about themselves. In this section of research, several lines from the list of posts were quoted, which are:

I. "Yesterday I wore something from 5 years ago and it actually still fits! So proud of myself! It was a scarf, but still. Let's be positive here" (04/03/2019)

II. "You are not fat, you have fat. You have fingernails, you are not fingernails." $(23 / 05 / 2019)$

III. "If we shouldn't eat at night, why do they put a light in the fridge?" $(03 / 04 / 2019)$

IV. "Potatoes make french fries, chips, and vodka. It's like the other vegetables aren't even trying" (07/03/2019)

Statements that are meant to be humorous can apparently be applied as a powerful sentence to boost confidence, taking lines (I) and (II) as two examples. In the first line, the speaker somewhat gives a cue about what she is going to talk about, which is something she used to wear. This hook is usually quite sensitive for those who are aware and insecure of their body size, because they expect a transformation where they can finally get to wear the clothes that fit their body and later assume that they have reached their confidence. This line ends with the funny twist where she is actually talking about wearing a scarf, which is a clothing element that doesn't require a certain body size. Assuming that her body has become bigger than it was five years ago, the act of deprecating herself by admitting that those clothes no longer fit her body denotes that she found acceptance within her. Here, self-deprecation helps boost the confidence that functions as a self-tool that encourages women and girls to carry out themselves. 
Meanwhile, the speaker in text (II) brings another impression towards herself by trying to persuade her audience her own way of seeing fat. In this text, the speaker somewhat tries to break the notion that fat is an adjective by comparing it with fingernails. This form of self-deprecation reflects the speaker's confidence to think that fat is not supposed to shape one's identity. Further lines tries to give quite a strong emphasis in dodging the actual occurrence, such as in text (III) and (IV) above. These two statements try to create humor through mixing up the realities (the light inside the fridge and potatoes as a produce that can be processed into different products) with the speaker's issues (the habit of eating at night and refusal to consuming other vegetables). In text (III), this distinctly denotes the speaker's confidence to perceive that diet habits aren't things she is into, indicating a soft rejection towards doing healthy habits that seem to be difficult to accomplish.

\section{Self-deprecation as a form of refusal towards painful exercise and companionship}

Failure in maintaining workout: speaking against painful exercise.

In order to achieve their dream body and become perceived as healthy, many women believe not only in the power of eating healthy and limiting their junk food intake, but also in the influence of working out which involves physical exercises. Tischner (2019) argued that Western society perceives physical health as narrowly linked to the mass of our body and weight loss that could be achieved through maintaining particularized health behavior. However, it is still difficult for some people to deny the fact that body exercise brings pain, so it requires a huge willingness and patience during the process. This apparently results in a chain of whines between individuals going through the same thing, which later leads them to seeing it as ridiculous and laugh at it. In Diet Starts Tomorrow page, utterances about struggling to do the body exercise are wrapped in a number of humorous self-deprecating tweet screenshots:

I. "My favorite part of jog is the 20 minutes I walk while deciding on a song before jogging for ten minutes" (04/05/2019)

II. "I get most of my workouts by forgetting stuff upstairs when I'm trying to leave the house" (23/05/2019)

III. "Forgot to go to the gym today. That's 3 years in a row now" (20/03/2019)

IV. "Sit-ups are the best exercise because they include the most lying down" $(13 / 03 / 2019)$

V. "I was gonna go to the gym but I literally just went last month, don't wanna overdo it" $(10 / 03 / 2019)$

Focusing on the first three statements, those lines appear to firstly communicate the speaker's routines: cardio exercises such as jogging and walking up the stairs, and going to the gym and do the physical exercise using sports equipment. They later bring up their failure in doing or maintaining the routines: walking and listening to music instead of jogging, walking up the stairs instead of doing a real workout, and forgetting to go to the gym. This indicates that they are actually aware of the fact that they need to stick to their routine in order to achieve the body shape that they desire, but hardly try to 
stay committed to it for it takes a lot of work. Instead of stressing about the pain, they jot it into a public written post in order to either become honest with their thoughts about exercise or look for another individual who are in the same boat. Here, deprecating oneself helps to keep the speaker from criticism and construct their ordinariness. Moreover, those self-deprecating lines try to express a disagreement towards painful exercise that is usually done with the intention of maintaining slim body. Another tweets such as statement (IV) and (V) emphasize the refusal towards physical exercise in a slightly different way, which makes it sound more like a dodging statement. In statement (IV), the speaker evades the fact that sit-ups are an important part in body exercise and talking about how good it is because it includes laying down. In statement $(\mathrm{V})$, the speaker evades her routine by confessing that she can't do the exercise often, saying it's not good to overdo it. In addition, these statements try to show that exercising is not something that all young women can enjoy.

\section{Frowning and fearing upon romance: showing vulnerability.}

Although it may not sound as either a humor or a direct self-deprecation, this theme entails a number of sarcastic expressions toward the trend couples who do workout together that somewhat reflect the speaker's vulnerability due to the fact that it doesn't happen to them. In this section, a number of lines containing jokes about the repugnance towards typical couples are quoted:

I. "A couple who lifts together will always stay... on my nerves" (30/04/2019)

II. "Saw a couple holding hands while jogging and it made me hopeful that one day I will meet someone who will hate them with me" (03/04/2019)

III. "People my age are having kids and I'm just here eating food off of paper towel because I don't want to wash a dish" (02/03/2019)

IV. "My biggest fear is I'm married and my husband says 'let's cut pizza out of our diet' and I have to leave with the kids in the middle of the night" (16/05/2019)

Analyzing the first two statements, one would assume that they are adapted from some popular optimistic quotes regarding typical young couple's life. Previous study has examined the function of partner as a support system for an individual in achieving certain purpose, including psychological health (Baucom, Kirby, and Kelly, 2009). However, one would argue that it might not be relevant to those who doesn't have one. Taking a closer look at the text, the speaker tries to carry the positive phrasing before twisting it into a pessimistic verdict. Instead of making it sound like a hate-speech, it appears to be a satirical punchline that somewhat evaluates woman's world. In statement (I), the speaker says that she hates it whenever she sees a couple doing sports together. In contrast, the speaker of statement (II) aims to seek for her audience to take her side in hating couples who does the exercise together. Moreover, a few tweets also express a pessimistic thoughts about the future change in life as an adult, as expressed in statement (III) and (IV). Through those statements, it indicates that some women may not feel prepared to move forward to becoming a typical adult dealing with typical gender norms, and feel as if being alone means little responsibility to bear. Having read about young women's humor preference which includes stories about everyday life, Coates (1996) in Crawford (2003) asserted that they apparently don't only function as 
self-deprecation, but are also tools to construct a "community of shared understandings" (p. 1413) about the absurdities that occur in life. Meaning, those lines try to reveal particularly women's vulnerability in order to not only engage with other women, but also to display oneself as ordinary in order to create a mutual understanding between one another more easily.

\section{CONCLUSION}

As a final recap, self-deprecating humor articulate young women's refutation towards diet culture and the thoughts about their body and surroundings. Selfdeprecation serves as a comfort space for women where overeating attitudes and statements of dodging diet culture are preached and validated, giving them an extra boost of confidence to live within their body by demonstrating a series of random written expressions about junk food consumption and the fat they have. As stated by Matwick and Matwick (2017), self-deprecation "protects them from judgment because she is the first to point out her flaws, such as lack of organization, control, and moderation" (p. 37). Morris (2019) also asserted that "fat activism is not enough to liberate them from oppressive structures, yet the process of "speaking fat" works to subvert discourses of fatness and provide comfort to fat women" (p. 143). Meanwhile, McKinley (2017) contended that "being fat may function as a form of resistance to gender ideologies for women" (p. 97). Based on the analysis, self-deprecation is also found out to serve as a means of criticizing the tormenting physical exercise that is commonly done by young women in order to achieve their thin ideal body, making it something they don't desire but are forced to do. Self-deprecating humor is also explored to have a power in building up mutual understandings between the speaker and the audience throughout revealing their vulnerability, particularly when it comes to occurrence like seeing a couple doing a physical exercise together or fearing about the future happenings where they can no longer do things as their wish.

However, attempts like publicizing self-deprecating humor apparently hasn't been adequate to help young women begin to feel good about their body and completely refrain from the toxic perception of diet culture that would lead them to a never-ending dissatisfaction towards their current shape. McKinley (2017) contended that "the ideologies of weight closely parallel to ideologies of woman-hood" (p. 110). This is due to the societal reality that young women are still constrained to have ideal body shape. Chapman and Maclean (1993) emphasized that it's important for young female to be successful in corresponding to their peer group expectations and advancing intimate relationships. Nevertheless, to maintain a slim figure is also assumed as "contributing to both goals" (p. 111).

Social media has indeed become an important aspect in the life of society that it provides them a space to express their thoughts, and at the same time delivers certain values that has long become perceived as the truth, such as how a woman should look like. It is, therefore, necessary to be critical enough when digesting a particular statement or judgement, specifically regarding the thoughts about diet culture. The idea of gathering the notions of anti-diet culture through a series of self-deprecating humor might have worked out as a tool for women's empowerment and self-acceptance. However, as stated by Jovanovski (2017), detrimental concepts of choice and 
empowerment are utilized to prolong their insecurity towards their body amidst the narratives related to identification of post-feminist and liberal-individualist. The research suggests further examination on how language is utilized to empower fat movement within the society of both gender. Further research might also be needed to focus on how the audience of the page react to the posts they have served as their feeds, and how it brings influence in the way particularly young women perceive diet culture.

\section{PRIMARY READING}

Apte, M. L. (1985). Humor and laughter: An anthropological approach. Cornell Univ Pr.

Crawford, M. (2003). Gender and humor in social context. Journal of pragmatics, 35(9), 1413-1430.

Gramsci, A. (1971). Selections from the Prison Notebooks of Antonio Gramsci. New York, International Publishers.

Green, E. (1998). 'Women doing friendship': An analysis of women's leisure as a site of identity construction, empowerment and resistance. Leisure studies, 17(3), 171-185.

Paltridge, B. (2006). Discourse Analysis: An Introduction. London: Continuum.

\section{REFERENCES}

Baucom, D. H., Kirby, J. S., \& Kelly, J. T. (2009). Couple-based interventions to assist partners with psychological and medical problems. Enhancing couples: The shape of couple therapy to come, 79-93.

Bell, S. (2018, May 6). On International No Diet Day, Resist Diet Culture [Blog post]. Retrieved from //www.sydneybell.ca/on-international-no-diet-day-resist-dietculture

Brown, Z., \& Tiggemann, M. (2016). Attractive celebrity and peer images on Instagram: Effect on women's mood and body image. Body image, 19, 37-43.

Chapman, G., \& Maclean, H. (1993). "Junk food" and "healthy food": meanings of food in adolescent women's culture. Journal of nutrition education, 25(3), 108113.

Cheng, D. C. M., \& Wang, L. (2016). Is laughing at yourself self-defeating? Selfdeprecating humor, humor style and persistence (WITHDRAWN). In Academy of Management Proceedings (Vol. 2016, No. 1, p. 11522). Briarcliff Manor, NY 10510: Academy of Management.

Clodfelter-Mason, J. (2019, April 15). Diet Culture: Examples of its Influence in Our Society [Blog post]. Retrieved from //www.cultivatejoynutrition.com/singlepost/2019/04/04/Diet-Culture-Examples-of-its-Influence-in-Our-Society 
Cohen, R., Fardouly, J., Newton-John, T., \& Slater, A. (2019). \# BoPo on Instagram: An experimental investigation of the effects of viewing body positive content on young women's mood and body image. New Media \& Society, 1461444819826530.

Cohen, R., Irwin, L., Newton-John, T., \& Slater, A. (2019). \#bodypositivity: A content analysis of body positive accounts on Instagram. Body image, 29, 47-57.

Cortés-Conde, F., \& Boxer, D. (2010). Humorous self disclosures as resistance to socially imposed gender roles. Gender \& Language, 4(1).

Eckler, P., Kalyango, Y., \& Paasch, E. (2017). Facebook use and negative body image among US college women. Women \& health, 57(2), 249-267.

Fardouly, J., \& Vartanian, L. R. (2016). Social media and body image concerns: Current research and future directions. Current opinion in psychology, 9, 1-5.

Fardouly, J., Willburger, B. K., \& Vartanian, L. R. (2018). Instagram use and young women's body image concerns and self-objectification: Testing mediational pathways. New Media \& Society, 20(4), 1380-1395.

Greengross, G., \& Miller, G. F. (2008). Dissing oneself versus dissing rivals: Effects of status, personality, and sex on the short-term and long-term attractiveness of self-deprecating and other-deprecating humor. Evolutionary Psychology, 6(3), 147470490800600303.

Harrison, C. (2018, August 10). What Is Diet Culture? [Blog post]. Retrieved from //www.christyharrison.com/blog/what-is-diet-culture

Holmes, J., \& Schnurr, S. (2006). 'Doing femininity' at work: More than just relational practice 1. Journal of Sociolinguistics, 10(1), 31-51.

Jovanovski, N. (2017). Femininities-Lite: Diet Culture, Feminism and Body Policing. In Digesting Femininities (pp. 59-101). Palgrave Macmillan, Cham.

Lee, J. Y., Slater, M. D., \& Tchernev, J. (2015). Self-deprecating humor versus otherdeprecating humor in health messages. Journal of health communication, 20(10), 1185-1195.

Matwick, K., \& Matwick, K. (2017). Self-deprecatory humor on TV cooking shows. Language \& Communication, 56, 33-41.

McKinley, N. M. (2017). Ideal weight/ideal women: Society constructs the female. In Weighty Issues (pp. 97-115). Routledge.

Morris, A. (2019). Fat Activism and Body Positivity: Freedom from Dieting?. In The Politics of Weight (pp. 143-179). Palgrave Macmillan, Cham.

Tischner, I. (2019). Tomorrow is the start of the rest of their life-so who cares about health? Exploring constructions of weight-loss motivations and health using story completion. Qualitative Research in Psychology, 16(1), 54-73.

Tosun, S., Faghihi, N., \& Vaid, J. (2018). Is an Ideal Sense of Humor Gendered? A Cross-National Study. Frontiers in psychology, 9, 199. 
Webb, J. B., Thomas, E. V., Rogers, C. B., Clark, V. N., Hartsell, E. N., \& Putz, D. Y. (2019). Fitspo at Every Size? A comparative content analysis of\# curvyfit versus\# curvyyoga Instagram images. Fat Studies, 8(2), 154-172.

Webb, J. B., Vinoski, E. R., Bonar, A. S., Davies, A. E., \& Etzel, L. (2017). Fat is fashionable and fit: a comparative content analysis of Fatspiration and Health at Every Size® Instagram images. Body image, 22, 53-64. 